\title{
Dinâmica Demográfica e uso da Terra no Cerrado Brasileiro: reflexões a partir da experiência do Padap
}

\author{
Mauro Augusto dos Santos' ${ }^{1}$, Alisson Flávio Barbieri², Gilvan Ramalho \\ Guedes $^{3}$, Carla Jorge Machado ${ }^{4}$ e José Alberto Magno de Carvalho ${ }^{5}$
}

Resumo: Com base nas teorias de desenvolvimento da fronteira e nas abordagens de estratégias de sobrevivência, este artigo ilustra o processo de colonização e dinâmica de uso do solo do Cerrado brasileiro, destacando a importância da migração, das associações agrícolas e do governo em contribuir para o sucesso de uma área de assentamento voltada para a intensificação de capital. Para ilustrar este processo com um estudo de caso, foi realizada uma pesquisa com os pioneiros na região do Programa de Assentamento Dirigido do Alto Paranaíba (PADAP) durante 2008 e 2009. Nossos resultados sugerem que a segunda geração procura emprego urbano e educação, com a migração rural-urbana se tornando uma componente chave da dinâmica de fronteira recente. O esvaziamento da fronteira, induzido pela emigração da segunda geração, parece funcionar como um incentivo, ao invés de uma restrição ao trabalho. Com uma combinação bem sucedida de provisão governamental de assistência técnica e crédito subsidiado pela Cooperativa Agrícola de Cotia, os pequenos agricultores foram capazes de adotar tecnologias de capital intensivo e experimentar novas culturas mais rentáveis, gerando maiores retornos agrícolas. Seguindo outros estudos que trabalham com a dinâmica de fronteira em outros lugares, este artigo contribui para a literatura através da combinação de teorias da economia e da geografia espacial, juntamente com quadros de desenvolvimento de fronteira, para compreender a dinâmica de uso do solo no Padap.

Palavras-chaves: Cerrado brasileiro, Padap, teorias de fronteira, agricultura, domicílios rurais, estratégias de sobrevivência.

1 Doutor em Demografia, Universidade Federal de Minas Gerais; Professor da Universidade Vale do Rio Doce. E-mail: mauroasantos@gmail.com.

$2 \mathrm{PhD}$, City and Regional Planning, University of North Carolina at Chapel Hill; Professor do Departamento de Demografia da UFMG. E-mail: barbieri@cedeplar.ufmg.br.

3 Doutor em Demografia, Universidade Federal de Minas Gerais; Professor da Universidade Vale do Rio Doce. E-mail: gilvan_guedes@brown.edu.

$4 \mathrm{PhD}$, Population Dynamics, Johns Hopkins University; Professora do Departamento de Medicina Preventiva e Social da UFMG. E-mail: cjmachado@terra.com.br.

5 PhD, Demography, London School of Economics; Professor do Departamento de Demografia da UFMG. E-mail: carvalho@cedeplar.ufmg.br. 


\begin{abstract}
Building on theories of frontier development and the livelihood approach, this paper illustrates the settlement process and land use dynamics of the Brazilian Cerrado, highlighting the importance of migration, agricultural unions and the government in contributing to the success of a settlement area towards capital intensification. To illustrate this process with a case study, we conducted a survey with the original settlers in the area assigned to the Programa de Assentamento Dirigido do Alto Paranaiba (PADAP) during 2008 and 2009. Results suggest that the second generation seeks urban employment and education, with rural-urban migration becoming a key component of the recent frontier dynamics. The hollowing out of the frontier, induced by the second generation outmigration, seems to work as an incentive, rather than a labor constraint. With a successful combination of government provision of technical assistance and subsidized credit by Cotia Agricultural Union, smallholders were able to adopt capital-intensive technologies and experiment with new and more profitable crops, yielding higher agricultural payoffs. Following other studies working with frontier dynamics elsewhere, this article contributes to the literature by combining theories of economics and spatial geography along with frontier development frameworks to understand land use dynamics in Padap.
\end{abstract}

Key-words: cerrado region in Brazil, Padap, frontier theories, agriculture, rural households, livelihood approach.

Classificação JEL: R14, R23.

\section{Introdução}

O Cerrado é o maior bioma brasileiro depois da Amazônia. Sua área engloba o estado de Goiás, o Distrito Federal e parte dos estados de Minas Gerais, Rondônia, Mato Grosso, Mato Grosso do Sul, Bahia, Tocantins, Maranhão, Piauí e Pará, totalizando cerca de $22 \%$ do território nacional (MMA, 1999). O Cerrado possui uma grande quantidade de espécies animais e vegetais, muitas delas endêmicas, e é considerado a mais diversificada savana do mundo (MMA, 1999; HOGAN et al., 2002; SAWYER, 2002). Ademais, o fato de seus lençóis freáticos alimentarem as nascentes que dão origem a seis das oito maiores bacias hidrográficas brasileiras também justifica a preocupação em se conservar este bioma (MMA, 1999; HOGAN et al., 2002; SAWYER, 2002).

O Cerrado brasileiro vem sofrendo um acelerado processo de degradação, provocado, principalmente, pela rápida expansão da agropecuária, iniciada na década de 1970 (RIBEIRO e GALIZONI, 2005). A partir desta época, com o desenvolvimento de novas tecnologias, tornou-se possível transformar seus solos, antes considerados impróprios para o cultivo agrícola, em terras extremamente produtivas. Com efeito, o desmatamento no Cerrado, acumulado até o início deste século, atingia $800.000 \mathrm{~km}^{2}$ (mais do que os $700.000 \mathrm{~km}^{2} \mathrm{da}$ Amazônia), correspondendo a 39\% da área total do Cerrado $\left(2.000 .000 \mathrm{~km}^{2}\right)$. Entre 2007 e 2008, as taxas de desmatamento do Cerrado estiveram em torno de $22.000 \mathrm{~km}^{2}$ ao ano (versus 11.000 $\mathrm{km}^{2}$ da Amazônia entre 2007 e 2008) (PIRES, 2000; MENEZES et al., 2009).

Este trabalho discute, com base em uma revisão da literatura e de uma pesquisa de campo, como uma região de assentamento dirigido do Cerrado mineiro, no Alto Paranaíba, pode exemplificar esse processo de ocupação do Cerrado brasileiro e seus consequentes impactos ambientais. $\mathrm{O}$ foco será sobre o papel da dinâmica demográfica sobre o processo de ocupação territorial e sobre as mudanças nas formas de uso da terra. A reconstituição histórica desse processo permite estabelecer as conexões entre a evolução dos domicílios agrícolas e suas estratégias de sobrevivência à medida que o assentamento passa de um estágio inicial de planejamento assistido para a condição de um espaço rural modificado pela integração e influência direta e indireta dos mercados urbanos que cresceram em seu entorno. O Programa de Assentamento Dirigido do Alto Paranaíba (Padap) serve como estudo de caso, tendo em vista esta proposta de compreender o papel da dinâmica demográfica na evolução das fronteiras agrícolas no Cerrado brasileiro. 


\section{Contexto histórico da implantação do Padap e o papel da CAC-CC}

O Programa de Assentamento Dirigido do Alto Paranaíba (Padap) foi implantado em 1973, em uma área de aproximadamente $600 \mathrm{~km}^{2}$, entre os municípios de São Gotardo, Rio Paranaíba, Ibiá e Campos Altos, em Minas Gerais (Figura 1). A área destinada ao projeto encontrava-se assim distribuída: Rio Paranaíba, com 60,8\% da área do projeto; Campos Altos, com 23\%; São Gotardo, com 10\%; e Ibiá, com 6,2\%. Em Campos Altos, a área destinada ao Padap representava 27,1\% da área do município; em Rio Paranaíba, 19,2\%; em São Gotardo, 7,1\%; e, em Ibiá, 1,4\%.

As características específicas dessa região explicam o interesse do governo em nela implantar o projeto de assentamento (FRANÇA, 1984; RIBEIRO e GALIZONI, 2005). Um argumento era a posição estratégica da região em relação aos principais mercados consumidores brasileiros Rio de Janeiro, São Paulo, Belo Horizonte e Brasília.
Ademais, a topografia era plana e bastante favorável à mecanização. Por último, a região já dispunha de uma infraestrutura adequada de energia e transporte, o que reduzia os custos de implantação do programa (SILVA, 2000).

A viabilização do Padap foi resultado do interesse da Cooperativa Agrícola de Cotia Cooperativa Central (CAC-CC), do governo do estado de Minas Gerais e do governo federal. Fundada em 1927, a partir da associação de um grupo de 70 agricultores da região de Cotia (SP), a CAC-CC tornou-se, nas décadas seguintes, uma das maiores cooperativas atuantes no Brasil, figurando entre as 20 maiores empresas nacionais (GONÇALVES e VEGRO, 1994). Após enfrentar sérios problemas financeiros, a CAC-CC foi liquidada extrajudicialmente em 1994, sendo suas instalações remanescentes na região do Padap incorporadas pela Cooperativa Agropecuária do Alto Paranaíba (Coopadap), criada nesse mesmo ano, e que ainda hoje é uma das grandes empresas da região (INFORMATIVO AGROMEN, 2006).

Figura 1. Municípios onde foi implantado o Programa de Assentamento Dirigido do Alto Paranaíba (Padap).

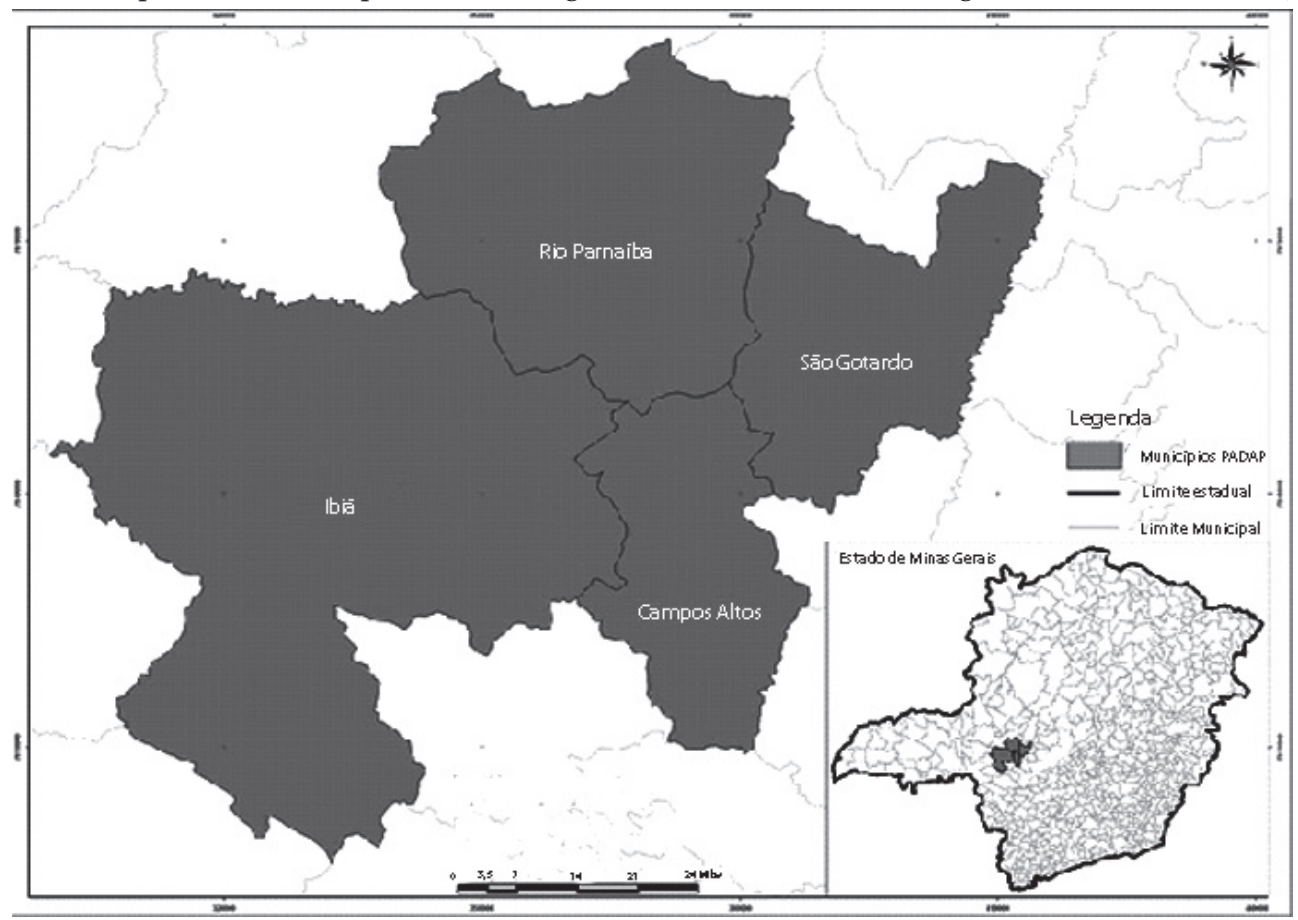

Fonte: IBGE, fonte básica de dados cartográficos: Microdados do Censo Demográfico de 2000; Projeção universal transversa de Mercatur (UTM) Datum AS D69 - fuso 23S; Elaborado por Glauco Umbelino, Cedeplar/UFMG. 
Na etapa posterior à desapropriação da área destinada ao projeto, a CAC-CC participou intensamente na implantação de toda a infraestrutura necessária para o seu funcionamento (FRANÇA, 1984; RIBEIRO e GALIZONI, 2005). Também ficou ao encargo da cooperativa a tarefa de selecionar os colonos que iriam adquirir os lotes dentro do projeto, os quais deveriam ser selecionados com base na capacidade tecnológica, econômica, financeira e administrativa de que dispusessem (FRANÇA, 1984; RIBEIRO e GALIZONI, 2005). Da área inicialmente desapropriada para a implantação do Padap, $255 \mathrm{~km}^{2}$ deram origem a 95 lotes que foram destinados aos colonos da CAC-CC, ficando a própria cooperativa com quatro lotes (FRANÇA, 1984).

O restante da área seria ocupado pelos pequenos produtores que tiveram suas terras desapropriadas. As terras foram devolvidas com a condição de que fossem exploradas nos mesmos padrões do Padap. Para isso, os produtores contariam com o apoio técnico e a infraestrutura montada para o projeto (FRANÇA, 1984). Contudo, praticamente todo o investimento e apoio técnico destinado ao Padap acabaram sendo direcionados à área compreendida pelos 95 lotes, ocupada pelos colonos da CAC-CC, uma vez que os remanescentes foram considerados, na época, agricultores com baixo conhecimento tecnológico e com limitadas aspirações comerciais (FRANÇA, 1984).

A CAC-CC teve papel fundamental para a produção agrícola no início do projeto, principalmente no apoio técnico aos cooperados, comercialização e financiamento. No caso do financiamento, quando o governo começou a restringir o volume de crédito rural no final da década de 1970, a CAC-CC passou a disponibilizar linhas de crédito para seus cooperados, provendo desde custeio para comercialização e investimento até adiantamento para compra de insumos e comercialização (FRANÇA, 1984; GONÇALVES e VEGRO 1994).

\section{A participação do Estado - além da CAC-CC}

A participação do Estado foi decisiva para a implantação e para o bom funcionamento do Padap, que se tornaria modelo para criação de outros projetos de colonização agrícola dentro do Cerrado brasileiro (FRANÇA, 1984; RIBEIRO e GALIZONI, 2005). Em primeiro lugar, como já destacado, a implantação do projeto só foi possível em decorrência da desapropriação de uma grande área, resultado de uma ação articulada entre a CAC-CC, o governo de Minas Gerais e do governo federal. Em segundo lugar, devem ser destacados os altos investimentos em infraestrutura, tais como a construção de estradas rurais, de armazéns, de silos e de redes de transmissão elétrica e de comunicação. Em terceiro lugar, houve o intenso apoio técnico prestado aos colonos pelas empresas de pesquisas estatais - principalmente da Embrapa, Emater (na época, Acar - Associação de Crédito e Assistência Rural), Epamig e Ruralminas (FRANÇA, 1984). Por último, houve a política de preços mínimos e as condições privilegiadas de financiamento colocadas à disposição dos agricultores pelas instituições financeiras ligadas aos governos estadual e federal (SILVA, 2000).

Deve-se ressaltar que, sem o desenvolvimento de novas técnicas de cultivo apropriadas ao Cerrado e de novas culturas adaptadas às características físicas e climáticas do bioma, a implantação do projeto, assim como toda a chamada "Revolução Verde", iniciada na década de 1970, seria impensável. Segundo Carvalho (2008), a Revolução Verde foi o fator que norteou os rumos da modernização agrícola no Cerrado, modificando radicalmente as bases econômicas, sociais e tecnológicas da agricultura brasileira. Com efeito, dado que o Padap foi o primeiro programa de colonização dirigida para o Cerrado (CARVALHO, 2008), pode-se assumir que o marco da Revolução Verde no Cerrado teve sua origem no Padap. 
Inicialmente, os agricultores envolvidos no projeto se beneficiaram do PCI (Programa de Crédito Integrado), uma linha de crédito oferecida pelo Banco do Desenvolvimento de Minas Gerais (BDMG). Além de contar com uma considerável soma de recursos disponíveis, o PCI apresentava condições de financiamento extremamente favoráveis. Esta linha de crédito estava disponível apenas aos grandes produtores, o que, como destacado por Salim (1986), fica evidente nas garantias exigidas para o financiamento - o agricultor deveria possuir bens, a serem utilizados como garantia do empréstimo, equivalentes ao valor do empréstimo, acrescido de $25 \%$. Além de juros baixos, os prazos para amortização da dívida eram bastante elásticos. Com a criação do Polocentro em 1975, os agricultores do Padap passaram a contar com as linhas de crédito deste programa, que eram ainda mais favoráveis que as do PCI (FRANÇA, 1984; SALIM, 1986).

\section{Os imigrantes do Paraná}

O fato de a escolha dos colonos pela CAC-CC ter se concentrado principalmente entre os seus associados do Paraná está ligado ao processo de ocupação da fronteira agrícola nesse estado. Este processo de ocupação foi iniciado na década de 1940, com a transferência da fronteira cafeeira do estado de São Paulo para o norte e noroeste paranaense. Devido a uma estrutura agrária na qual prevaleciam pequenas e médias propriedades, entre as décadas de 1940 e 1960, a população do Paraná, devido ao grande influxo de migrantes, cresceu a taxas bem maiores que as nacionais, quintuplicando no final do período. A partir da década de 1970, com a introdução de culturas menos intensivas em mão de obra - principalmente soja, o milho e arroz -, que necessitavam de grandes extensóes de terras, e devido também ao avanço da tecnologia agrícola poupadora de uso de mão de obra, o Paraná passou a expulsar população, apresentando, no período, o menor crescimento demográfico entre as unidades da federação brasileiras (MAGALHÃES, 2003).
O papel do mercado de terras também é fundamental para se entender o movimento migratório dos agricultores do Paraná para a região do Padap. A questão da valorização da terra no estado de origem destes imigrantes, associada ao baixo preço das terras do Cerrado (dado, principalmente, que o Padap foi o primeiro projeto de colonização implantado, nos moldes da moderna agricultura, dentro deste bioma), certamente possibilitou a aquisição de grandes extensões de terras no Cerrado mineiro, com base na venda de pequenas propriedades no Paraná, ou de uma pequena soma de economias acumuladas ${ }^{6}$.

Survey realizado no período de agosto de 2008 a abril de 2009 identificou todos os 52 produtores rurais que, na época da realização da pesquisa, eram os proprietários dos 95 lotes que deram origem ao Padap. Destes, 29 (55,8\%) responderam ao questionário que continha questões relacionadas às características individuais e de mobilidade, ao ciclo de vida domiciliar e às mudanças no uso da terra (SANTOS, 2010). Este survey revelou o que a literatura vem consistentemente indicando: os motivos que teriam levado os produtores rurais a deixarem suas antigas propriedades relacionavam-se à quantidade insuficiente de terras e à baixa renda gerada pelas propriedades familiares. Como justificativa de escolha da região do Padap como local de destino, entre os primeiros colonos, a alegação foi de que as terras do Padap possuíam baixo preço; a facilidade de

\footnotetext{
6 Segundo Sasaki (2008), um dos pioneiros na colonização do Padap, o preço da terra na região do Padap era dez vezes mais barato que o da terra de cultura na mesma região. Se considerarmos essa relação com as terras de cultura do Paraná, que na época estavam supervalorizadas, tem-se um bom indicador de um dos motivos que levaram pequenos agricultores do Sul do País a se tornarem rapidamente médios e grandes produtores em Minas Gerais. Segundo Resende (2002, p. 4), as terras de lavoura do Paraná valiam, no período de 1977 a 1979, em torno de cinco vezes o valor das terras de lavoura no Cerrado. $\mathrm{O}$ autor ressalta que, analisando dados até 2000, as terras de lavoura em São Paulo e no Paraná valeriam mais de dez vezes o valor das terras virgens do Cerrado mato-grossense, que, com certeza tinham um valor bem maior do que o atribuído às terras de Cerrado na região do Padap na época em que foi implantado o projeto de colonização, uma vez que a prática da agricultura nestas terras era tido como algo impossível.
} 
crédito e o apoio técnico recebido na época por empresas de pesquisa estatais (SANTOS, 2010). O estudo revelou, ainda que, para produtores que se dirigiram ao Padap em anos mais recentes (entre 1990 e 1999), a presença de amigos e parentes na região revelou-se mais importante do que outrora (SANTOS, 2010).

Dados do estudo de Santos (2010) também indicaram uma ideia do tamanho do domicílio na época na qual o imigrante chegou à região do Padap. Do total de produtores rurais que imigraram para a região, mais de $70 \%$ imigraram com pelo menos o cônjuge. Assim, a migração familiar é algo característico dos produtores do Padap.

\section{Características do Padap}

Desde a sua implantação nos anos 1970 até o final da década de 1980, o Padap apresentou uma característica que predomina nas demais áreas de produção agrícola no Cerrado: a quase totalidade de sua área plantada era ocupada por commodities agrícolas, principalmente soja, milho e café. França (1984) aponta que a divisão da área cultivada em 1983 era a seguinte: 75\% de sua área estava ocupada com soja, $13 \%$, com milho e $12 \%$, com café.

No final da década de 1980, o preço da cenoura subiu consideravelmente, estimulando os agricultores da região, cujo microclima é bastante favorável ao seu plantio e de outras leguminosas, a investirem no seu cultivo. A partir do início do cultivo da cenoura e posteriormente com a introdução de novas culturas - como batata, cebola, alho, beterraba, abacate, entre outras -, a produção agrícola da região tornou-se extremamente diversificada, passando a soja e o milho a serem utilizados mais para a rotação de culturas do que para venda ao mercado. A agricultura na região passou a ser bastante intensiva, com as propriedades produzindo durante todo o ano, e não apenas tendo uma ou duas safras, como acontecia com a soja, o milho e o café, produtos que antes predominavam na região. Além do uso mais intensivo da terra, a utilização de tecnologias modernas de cultivo também favoreceu o aumento da produção (REVISTA AGROCAMPO, 2009).

Dados mais recentes, relativos ao survey conduzido por Santos (2010) e tendo como referência o ano de 2007, indicam que mais da metade dos produtores entrevistados se dedicavam ao cultivo de soja, milho, café e trigo em até 580 hectares de terra e quase um quarto dos entrevistados cultivavam estas commodities em áreas superiores a 580 hectares. Já o cultivo de tubérculos, cenoura, batata, beterraba e cebola, foi relatado por quase $40 \%$ dos entrevistados para áreas de até 300 hectares; cerca de 15\% dos entrevistados revelaram cultivar estes mesmos tubérculos em área superior a 300 hectares (SANTOS, 2010). Finalmente, quase metade dos produtores se dedicava ao cultivo de alho. Estas informações são úteis por algumas razões: em primeiro lugar, destaca-se a diversificação da agricultura, o que torna a região atraente para trabalhadores rurais, que podem ter empregos durante todo o ano (SANTOS, 2010). Em segundo lugar, revela o que França (1984) já havia constatado, o aumento do tamanho médio das propriedades, que passou de 270 hectares em 1974 para 344 hectares em 1983. Estes dados corroboram os resultados de Santos (2010), que indicam que o tamanho médio da primeira propriedade era de 275 hectares, passando para 451 hectares em 2007, apontando, assim, para um aumento da concentração fundiária na região.

\section{Perfil do agricultor no Padap}

As chamadas "abordagens de estratégias de sobrevivência" (livelihood approaches) têm sido muito utilizadas em estudos sobre áreas de fronteira para descrever as formas como domicílios rurais mobilizam os recursos disponíveis para garantir a geração de renda e bem-estar (ELLIS, 2000; DE SHERBININ et al., 2008). Nas abordagens de estratégias de sobrevivência, os membros dos domicílios se engajam em diferentes atividades com o objetivo de sobreviver e prosperar. A definição do portfólio de atividades dependerá da capacidade dos domicílios, enquanto estratégia 
coletiva, de mobilizar os recursos, ou os tipos de capital, à sua disposição (DE SHERBININ et al., 2008):

Natural capital: the natural resource stock, or local environmental endowment (including water, wind, soil, forest resources); Social capital: the social resources (networks, membership of groups, relationships of trust, access to wider institutions of society) upon which households may draw; Human capital: including formal and informal education, local ecological knowledge, the ability to work, and good health; Physical capital: including productive assets held by the household (land, tools, oxen) as well as communal assets to which they have access (roads, communication infrastructure such as radio broadcasts); Financial capital: typically, the most fungible of assets, including cash savings, supplies of credit, or regular remittances and pensions (p. 3).

O valor final do bem-estar e prosperidade dos domicílios será uma combinação, em proporções variadas, dos cinco tipos de capital descritos. Swinton et al. (2003) acrescentam que a distribuição relativa dos capitais é tão importante quanto o seu nível (ou valor individual) para a manutenção do bem-estar dos domicílios rurais. Dado que alguns capitais são pouco líquidos, a sua capacidade de geração de bem-estar é diretamente influenciada pela sua relação com os demais capitais. Ao existirem conjuntamente, um capital não líquido pode servir como um colateral implícito para potencializar os efeitos de outro capital sobre o valor final do bem-estar e da prosperidade desses domicílios.

O perfil do agricultor do Padap pode ser descrito em termos de seu capital, na forma discutida acima. Em relação ao capital financeiro, embora a maior parte dos pioneiros do Padap tenham tido como origem pequenos domicílios no Paraná (FRANÇA, 1984), esses agricultores trouxeram para o Padap alguma soma de recursos. Isso se deu pela própria seletividade do projeto em relação às características das famílias selecionadas pela CAC-CC (as quais deveriam ser selecionados com base na capacidade tecnológica, econômica, financeira e administrativa), garantindo maior familiaridade com inovações tecnológicas e a capacidade de arcar com os custos iniciais e manutenção da própria unidade domiciliar (FRANÇA, 1984). Segundo França (1984), além de outros fatores importantes de atratividade do projeto (como provimento governamental, proximidade com os mercados consumidores e infraestrutura básica), produtores rurais relataram, como um dos principais motivos que os levaram a imigrar para a região, o apoio recebido da CAC-CC, incluindo o provimento de crédito.

Também contaram com capital humano de qualidade. A capacidade tecnológica era outro pré-requisito de seleção dos produtores para o projeto. Segundo França (1984), os produtores rurais, antes de migrarem para o Padap, cultivavam, em suas regiões de origem, basicamente o café, a soja e o trigo. Ou seja, estes agricultores já possuíam os conhecimentos necessários para o cultivo desses produtos e, no Padap, utilizariam esses conhecimentos em um novo tipo de clima e solo, tarefa na qual foram auxiliados pelas empresas estatais de pesquisa (FRANÇA, 1984). Assim, a maior parte dos colonos possuía bom domínio das técnicas modernas de cultivo agrícola, estando, inclusive, familiarizados com a agricultura altamente mecanizada (SAZAKI, 2008). Dados do estudo de Santos (2010) indicam, ainda, que o nível de escolaridade dos primeiros colonos era sensivelmente superior ao de outros dirigentes de estabelecimentos agropecuários no Brasil.

Em se tratando do capital social, os agricultores do Padap também contaram com uma rede social bastante eficiente, principalmente a partir da atuação da CAC-CC, já descrita. Como os pioneiros eram, na grande maioria, descendentes de japoneses vindos do Paraná, criou-se uma identidade de grupo, o que fortaleceu ainda mais a rede social, facilitando a chegada, após os primeiros anos de implantação do projeto, de novos grupos de colonos (RIBEIRO e GALIZONI, 2005), o 
que também foi corroborado por Santos (2010). O survey indicou que alguns dos colonos que se mudaram entre 1990 e 1999 decidiram aplicar seu próprio capital na região, o que revela dois pontos importantes: 1) a importância do capital social aumentou com o passar dos anos na região do Padap e 2) o capital social influenciou diretamente a conversão de capital financeiro em investimento produtivo, corroborando o argumento de Swinton et al. (2003) sobre a relevância da distribuição e inter-relação entre os capitais em contextos rurais. Finalmente, em termos de capital físico, os agricultores do Padap têm vias de acesso para os principais mercados consumidores do País e dispõem de meios modernos para se comunicarem e ter acesso rápido a informações (FRANÇA, 1984; RIBEIRO e GALIZONI, 2005). Num contexto de assentamento agrícola que já nasceu com uma forte orientação comercial, a disponibilidade de infraestrutura e a proximidade aos mercados consumidores tornam-se fatores-chave, os quais ao mesmo tempo reduzem o custo de transporte e viabilizam o cultivo de um maior número de culturas agrícolas (tanto perecíveis quanto não perecíveis).

Observa-se que a combinação das formas de capital descritas compensou e, eventualmente, reverteu as desvantagens comparativas de capital natural na região do Cerrado para o cultivo de grãos de alta rentabilidade em relação à região de origem dos colonos. Dessa forma, pôde-se viabilizar, com base em alta presença de capitais financeiro, físico, humano e social, a agricultura comercial no Cerrado mineiro.

\section{Abordagens de fronteiras agrícolas: o que acrescentam ao entendimento do Padap?}

"Fronteira" denota, essencialmente, um conceito dinâmico. Pode-se pensar que a expansão da fronteira foi (e é) a desencadeadora dos processos de modernização capitalista do Cerrado. Segundo Inocêncio e Calaça (2009), a fronteira surge como uma categoria útil para análise da expansão e penetração do capital nas áreas rurais.
Neste contexto de incorporação de novas áreas, a região do Cerrado tornou-se estratégica devido à sua posição geográfica e características físico-ambientais. Ademais, houve o esgotamento de terras disponíveis para a agricultura intensiva no Sul e no Sudeste (SILVA, 2000). Neste sentido, cabe destacar aspectos ligados à evolução da fronteira utilizando informações sobre o Padap, à luz de duas abordagens teóricas recentes discutidas a seguir. Tais abordagens têm como enfoque uma dimensão estrutural, ou o contexto em que decisões domiciliares (conforme retratada pelas abordagens de estratégias de sobrevivência) são tomadas. As abordagens estruturais são destacadas na sequência, assim como suas adequações ao caso do Padap.

\section{Abordagem dos estágios de fronteira}

A abordagem dos estágios de fronteira utiliza a ideia de uma fronteira inteira (como uma região de assentamento) para explicar o seu desenvolvimento ao longo do tempo (GUEDES, 2010). Essa perspectiva parte do princípio de que a fronteira evolui em fases que se sucedem, respondendo à experiência, necessidades e recursos disponíveis pelos domicílios (HENKEL, 1982; MORAN, 2008). Esse arcabouço chama atenção para a dinâmica do ambiente institucional que acompanha a evolução da região. Henkel (1982) sugere que as fronteiras passam por quatro estágios: o estágio pioneiro; o estágio da comercialização; o estágio do abandono e, por fim, o estágio da consolidação e revitalização.

O estágio pioneiro corresponde ao início do processo de colonização, com a chegada das famílias de agricultores, no qual predominam altas taxas de desmatamento e produção de anuais para subsistência. $O$ estágio da comercialização é caracterizado pelo crescente envolvimento das famílias com os mercados locais em desenvolvimento, gerando novas possibilidades de venda da produção, de especialização em culturas de alto valor comercial e de diversificação da mão de obra familiar entre 
setores da economia. No estágio do abandono, as famílias, frente à limitada base de recursos, à disponibilidade de terra e à escassez de mão de obra, abandonam a terra com fertilidade em declínio e avançam para novas frentes rurais. No estágio da consolidação e revitalização, os lotes abandonados são comprados por grandes fazendeiros ou empresas rurais ou incorporados pelos colonos sobreviventes.

A abordagem dos estágios da fronteira, portanto, prevê uma dinâmica para as áreas de fronteira esquematizada em fases, partindo da fase pioneira até chegar à fase de consolidação/ revitalização. Essa abordagem evolucionista assume três pressupostos restritivos: os domicílios dos colonos migram para a fronteira ao mesmo tempo, ignorando as evidências de que o processo de colonização pode se estender por mais de duas décadas (MORAN, 1981; SMITH, 1982); o domicílio nuclear é a figura-chave como elemento de colonização da fronteira (D'ANTONA, VANWEY e HAYASHI, 2006); e o último estágio é bem caracterizado, impossibilitando cenários alternativos, como na trajetória de transição geracional, na qual não há abandono, consolidação ou fragmentação, mas apenas mudança no controle da propriedade rural dos pais para os filhos.

\section{A abordagem dos estágios de fronteira e o Padap}

A principal contribuição da teoria dos estágios de fronteira é informar sobre o dinamismo destas fronteiras, adicionando uma dimensão temporal aos domicílios e às instituições que se estabelecem no interior e no entorno das fronteiras agrícolas (GUEDES, 2010).

No caso do Padap, o estágio pioneiro não se refere à subsistência (SANTOS, 2010). O estágio de comercialização existe desde a implantação do projeto que surge já totalmente inserido no mercado - o que ocorreu foi um aumento gradativo e a diversificação da produção (SANTOS, 2010). Há evidências de que o estágio da consolidação e revitalização ocorreu, com a entrada de novos produtores e o aumento do tamanho das propriedades na região, conforme mencionado. Estas evidências encontram-se em Santos (2010) e em França (1984).

No Padap, houve mais de um grupo de colonos chegando em épocas distintas. Foram identificadas diferentes grupos de assentados: o dos chamados pioneiros - Santos (2010) chama de pioneiros os que chegaram à região do Padap em 1974 - e os demais, que chegaram a região entre 1975 e 1979, entre 1980 e 1989 e entre 1990 e 1999. Nesse aspecto, há, no caso do Padap, uma maior dinamicidade temporal das migrações dos colonos, o que contradiz o primeiro pressuposto da abordagem dos estágios de fronteiras, ou seja, a de que os domicílios dos colonos migrariam para a fronteira ao mesmo tempo.

O domicílio nuclear, conforme observado por Santos (2010) é a figura-chave. Há o agricultor que é ajudado pela esposa e filhos ou, quando não, por um administrador contratado. No Padap ocorrem transição geracional, consolidação e fragmentação (SANTOS, 2010). Os casos de consolidação e fragmentação são mais comuns, o que pode ser explicado pelo fato de que a maioria dos agricultores (pioneiros e os que chegaram na década de 1980) ainda está no comando de suas propriedades. Outra possibilidade, não rara, conforme Santos (2010), é os filhos venderem as propriedades herdadas justamente por se dedicarem a atividades não relacionadas à agricultura, por exemplo, aquelas de base urbana (SANTOS, 2010).

\section{Abordagem da geografia econômica e espacial}

As perspectivas baseadas na geografia econômica e espacial baseiam-se em princípios tais como a distância do produtor em relação ao mercado e as taxas marginais de retorno específicas por produto agrícola. Essas perspectivas assumem um desenvolvimento linear da fronteira baseado na eliminação das diferenças regionais dos mercados no longo prazo à medida que os fluxos 
de bens, serviços e fatores de produção são livremente intercambiados (HOSELITZ, 1963). Como consequência, todas as formas de atrito são tidas como barreiras ao desenvolvimento. O investimento em infraestrutura (especialmente a expansão da estrutura viária) é uma das principais formas previstas por essas perspectivas para facilitar a troca de recursos entre as regiões e acelerar o processo de redução das assimetrias regionais.

Aplicada à organização do uso do solo em fronteiras agrícolas, a teoria da geografia econômica e espacial argumenta que os sistemas de uso do solo são uma função direta da receita obtida com o cultivo de cada cultura agrícola. Os modelos de bid-rent (THÜNEN, 1966 [1826]) destacam o papel do acesso aos mercados (e custos de transporte) para determinar o uso ótimo do solo. Como os custos variam com a perecibilidade e a dificuldade de manejo, cada cultura apresenta seu próprio retorno dentro de um limite espacial de cultivo comercial. Assim, a qualquer distância, a cultura que retorna a maior receita é cultivada e a estrutura espacial de uma região passa a ser determinada pelo conjunto das curvas de receita obtida pelas diferentes culturas.

Desse modo, propriedades rurais próximas aos centros urbanos são usadas para o cultivo de culturas de maior valor comercial e de alta perecibilidade (como tomates, frutas, entre outras). Terras mais afastadas do mercado são usadas para culturas de menor valor comercial e de menor perecibilidade (como melóes, batatas e gado), ao passo que terras em áreas marginais serão destinadas à agricultura de subsistência (WALKER,2003;THÜNEN1966[1826]).Aprincipal predição desses modelos é a de que os lotes em áreas de menor acessibilidade especializam-se na produção para autoconsumo, ou combinam culturas anuais e criação degado, dado que o gado pode ser transportado até o mercado (VANWEY, GUEDES e D'ANTONA, 2008).

Vários estudos confirmam a importância do tamanho e a distância ao mercado para a organização do uso do solo (por exemplo, GUEDES, 2010 e GUEDES et al., 2010). Em consequência, alguns autores propõem a expansão e a melhoria das vias de acesso em áreas previamente colonizadas nas regióes de fronteira como uma forma de elevar o preço da terra e de reduzir o preço de produtos alimentícios nas áreas urbanas (PFAFF et al., 2009). A melhoria do preço e a redução dos custos possibilitariam a intensificação tecnológica e o melhor uso do solo, desencorajando práticas de manejo ambientalmente não desejáveis (ANDERSEN et al., 2002).

\section{Geografia econômica e espacial e o Padap}

Uma forma de agregar poder analítico à abordagem da geografia econômica e espacial é buscar, nas perspectivas baseadas em economia, elementos que permitem compreender como as questões espaciais e geográficas se associam às transformações geradas pela penetração das relações capitalistas de produção na economia camponesa (ou de pequenos agricultores) e tendem a expulsar a população rural de seu contexto. No caso de São Gotardo, município da região do Padap, houve crescimento zero durante a década de 1970, mesmo com a chegada de imigrantes, pois a implantação do projeto (e o seu sucesso) fez com que pequenos produtores rurais vendessem suas terras e emigrassem (SANTOS, 2010).

Com relação à pós-fronteira no Padap, esta realmente foi caracterizada pela remoção da cobertura vegetal nativa de toda a área possível de ser mecanizada, o que tem obrigado os agricultores a comprarem terras nos municípios vizinhos simplesmente para servirem de reserva legal (área preservada) ${ }^{7}$. Como a região não é toda plana, as matas ciliares não sofreram grandes danos, devido ao fato de os cursos d'água se situarem em locais de difícil acesso para máquinas. O tipo de solo e a agricultura moderna sempre permitem a correção: ou seja, a grande vantagem do Cerrado é a possibilidade de se

\footnotetext{
7 A legislação brasileira define que sejam destinadas, como reserva legal, $35 \%$ das propriedades localizadas nas áreas de Cerrado que estão inseridas dentro da Amazônia Legal. Para as propriedades dentro do Cerrado, mas fora da Amazônia Legal, esse percentual cai para apenas $20 \%$.
} 
'fazer o solo', ou seja, corrigi-lo (ABELSON e ROWE, 1987; CUNHA, 1994; REZENDE, 2002). A migração de agricultores, com a busca de novas terras em outras áreas do Cerrado, se dá mais pelas limitações de terras agriculturáveis (planas e passíveis de mecanização) no entorno do projeto. A questão da agricultura familiar foi sentida em São Gotardo no início da implantação do projeto, quando as terras passaram, em poucos anos, a serem buscadas por agricultores que desejavam expandir suas atividades dentro de um contexto de disponibilidade de crédito em condições ótimas. Na região, a agricultura familiar, ou em pequena escala, visa mais atender ao mercado local e não a responder à demanda externa (SANTOS, 2010).

\section{Conclusões}

Este artigo teve como foco o estudo de caso do Padap, buscando compreender sua implantação e evolução à luz de teorias e relatos, além de um survey realizado com os primeiros produtores. As evidências indicam claramente que a criação do Padap só foi possível devido a uma junção de interesses. De um lado, os governos de Minas Gerais e federal estavam interessados em implantar uma agricultura altamente moderna e de base técnica avançada que gerasse crescimento econômico não apenas a partir do aumento da produção agrícola, mas, principalmente, pela expansão das indústrias de insumos e de máquinas destinadas a essa atividade (FRANÇA, 1984; SALIM, 1986). Do outro lado, a CAC-CC estava interessada em ampliar a sua área de atuação no País e em garantir aos filhos de seus cooperados, com a indisponibilidade de terras no Paraná, as condições para que pudessem continuar a ser agricultores.

Além da proposta inicial de assentamento dirigido, as características da própria região já apontavam para a rápida transformação de uma área que era baseada em produção familiar para uma consolidação da produção voltada ao mercado. As próprias instituições envolvidas no processo, como a CAC-CC, já apontavam para uma iniciativa agrícola de caráter comercial, embora gerida por famílias, especialmente quando da sua implementação.

O projeto nasceu inserido no mercado consumidor. Por ser uma espécie de projeto-piloto, escolheu-se uma região com fácil acesso para escoar a produção, além da escolha dos produtos que seriam produzidos, todos commodities agrícolas.

A mudança no uso do solo na região - início do cultivo de hortaliças - respondeu a uma mudança tecnológica - desenvolvimento da espécie de cenoura "brasília" - que possibilitou a exploração de uma cultura em larga escala no Cerrado. A mudança atendeu a uma alta demanda do mercado por esse produto. Os primeiros agricultores que cultivaram cenoura em escala comercial obtiveram grandes safras de um produto escasso e, portanto, caro.

Ressaltou-se, também, que a região já tinha uma agricultura moderna e mecanizada, o que facilitou a introdução de outras culturas, com grande demanda e que necessitam de grande investimento em tecnologia para a produção, como a batata e o alho - a região já é a segunda maior produtora desse produto no Brasil.

Cabe comentar, ainda, o papel das redes sociais, que se desenvolvem endogenamente à região e, uma vez estabelecidas, facilitam a tomada de decisão sobre o uso da terra entre pequenos agricultores (BEBBINGTON, 1999). Por exemplo, o estabelecimento de redes sociais de ajuda e informação (como as associações e cooperativas agrícolas) e as redes familiares possibilitaram a mudança para sistemas de uso do solo de maior retorno ao disponibilizarem informação (conhecimento técnico) e recursos (crédito e dinheiro), capazes de substituir ou complementar a mão de obra familiar na adoção de sistemas comercialmente mais rentáveis (WOUTERSE e TAYLOR, 2008; STARK e LUCAS, 1988). O papel das redes sociais no Padap é marcante no processo de implantação - o papel da CAC-CC na escolha dos colonos entre os seus cooperados é evidente - e de migração dos parentes na década de 1980, neste caso, com o 
fornecimento de informações e o suporte aos imigrantes recém-chegados.

Buscou-se uma reflexão sobre o processo de colonização do Padap a partir das teorias de fronteira agrícola. O objetivo foi, com base nas abordagens, compreender o passado e predizer mudanças futuras na região. Essas teorias enfatizam o papel exógeno e de uso intensivo de tecnologias na mecanização das terras do Padap e retratam as condições estruturais a partir das quais as decisões dos imigrantes e de seus domicílios são tomadas. Nesse último aspecto, é notório como a alta intensidade de capital financeiro, físico, humano e social dos colonos contribuiu para o sucesso do Padap em termos da consolidação de uma agricultura comercial altamente dinâmica e lucrativa. A gênese desse processo pode ser localizada na alta seletividade da imigração para a região, com a seleção, pela CAC-CC, de famílias de colonos com alta dotação de capital na forma descrita.

Destaca-se finalmente, o grande apoio do governo federal e estadual e de suas empresas de pesquisa, por meio de financiamento, disponibilização de crédito, políticas de preços mínimos, além do apoio técnico oferecido aos produtores rurais, o que garantiu um contexto imprescindível para o sucesso do Padap. A seleção, feita pela CAC-CC, de migrantes com elevado capital humano, físico, financeiro e mesmo social, possibilitaram que o Padap se tornasse o que é hoje: uma região com agricultura diversificada e altamente mecanizada.

\section{Referências bibliográficas}

ABELSON, P. H. e ROWE, J. W. "A New Agricultural Frontier". Science, New Series, United States, v. 235, n. 4795, p. 1450-1451, mar, 1987.

ANDERSEN, L. E., et al. The dynamics of deforestation and economic growth in the Brazilian Amazon. Cambridge: Cambridge University Press, p. 282. 2002.

BECKER, B. K. "Os eixos de integração e desenvolvimento e a Amazônia". Revista Território, Rio de Janeiro, v. 4, n. 6, p. 29-42, jan./jun. 1999.
CARVALHO, N. D. "Territorialização do capital: as políticas públicas para o campo na Mesorregião do Triângulo Mineiro/Alto Paranaíba - MG". In: IV Encontro Nacional de Grupos de Pesquisa - ENGRUP, São Paulo, p. 818$837,2008$.

CUNHA, A. S (coord.) Uma avaliação da sustentabilidade da agricultura nos cerrados. Brasilia, IPEA, p. 204. 1994.

D'ANTONA, A. O., VANWEY, L. K. e HAYASHI, C. M. "Property size and land cover change in the Brazilian Amazon. Population and Environment", New York, v. 27, n. 5-6, p. 373-396, May 2006.

DE SHERBININ, A., et al. Rural Household Micro-Demographics, Livelihoods and the Environment. Artigo em revisão em Global Environmental Change. 2007.

ELLIS, F. Rural Livelihoods and Diversity in Developing Countries. Oxford University Press: Oxford, p. 296. 2000.

FRANÇA, M. O cerrado e a evolução recente da agricultura capitalista: a experiência de Minas Gerais. Dissertação de mestrado. Belo Horizonte, Cedeplar, Universidade Federal de Minas Gerais, p. 169. 1984.

GONÇALVES, J. S. e VEGRO, C. L. R. "Crise econômica e cooperativismo agrícola: uma discussão sobre os condicionantes das dificuldades financeiras da Cooperativa Agrícola de Cotia (CAC)". Agricultura em São Paulo, São Paulo, v. 41, n. 2, p. 57-87, 1994.

GUEDES, G. R. Ciclo de vida domiciliar, ciclo do lote e mudança no uso da terra na Amazônia Rural Brasileira - um estudo de caso para Altamira, Pará. Teses de Doutorado. Belo Horizonte, Cedeplar, Universidade Federal de Minas Gerais, p. 223. 2010.

GUEDES, G. R., et al. Poverty Dynamics, Ecological Endownments and Land Use among Smallholders in the Brazilian Amazon. In: European Population Conference, Viena, Austria. Anais. 2010.

HOGAN, D. J., et al. (orgs.). Migração e ambiente no CentroOeste. Campinas, Nepo/Unicamp: PRONEX, p. 324. 2002.

Informativo AGROMEN. Ano V,n.21, Orlândia, SP. 2006. http://www.agromen.com.br/site/informativos/21.pdf (acesso em 04 de setembro de 2010).

INOCÊNCIO, M. E. e CALAÇA, M. “Cerrado: Fronteira da produção agrícola capitalista do século XX" In: Anais do XIX Encontro Nacional de Geografia Agrária, p. 1-16. 2009.

MAGALHÃES, M. V. Paraná e suas regiões nas décadas recentes: as migrações que também migram. Tese de doutorado. Belo Horizonte, Cedeplar, Universidade Federal de Minas Gerais, p. 195. 2003.

MENEZES, B. B., et al. "Uso e ocupação agropecuária no Cerrado brasileiro; transformações da paisagem e seus 
impactos ambinetais no estado de Goiás". In: 12º Encuentro de Geógrafos de América Latina, 2009, Montevideo. Caminando en una América Latina en Transformación, p. 13.2009.

MINISTÉRIO DO MEIO AMBIENTE (MMA) Agenda 21 Brasileira - Agricultura sustentável - Produto 3 / Versão final. Museu Emílio Goeldi / USP-PROCAM / ATECH. (disponível no site www.fea.unicamp.br/ docentes/ortega/curso/docfinal.rtf ), 1999.

MORAN, E. F., BRONDÍZIO, E. S. e MCCRACKEN, S. D. "Trajectories of land use: soils, succession, and crop choice". In: WOOD, C. H.; PORRO, R. Deforestation and land use in the Amazon. Gainesville, University Press of Florida, p. 193-217. 2002.

PFAFF, A. et al. "Road impacts in Brazilian Amazonia". In: KELLER, M., BUSTAMENTE, M., GASH, J. e DIAS, P. (Ed.). Amazonia and global change. Washington: American Geophysical Union, p. 565. 2009.

PAN, W. K. Y. et al. "Forest clearing in the Ecuadorian Amazon: a study of patterns over space and time". Population and Research Policy Review, Amsterdam v. 26, n. 5-6, p. 635-659, Dec. 2007.

PIRES, M. O. "Programas agrícolas na ocupação do cerrado". Sociedade e Cultura, Uberlândia, v. 3, n. 1 e 2, p. 111131, Goiânia, jan/dez, 2000.

POMPERMAYER, M. J. The state and the frontier in Brazil: a case study in the Amazon. 1979. Tese de Doutorado Department of Political Science, Stanford University, 1979.

Revista Agrocampo. Ano 1, n.1, São Gotardo, MG, julho 2009. http://www.revistaagrocampo.com.br/Reportagem Cenoura.html (acesso em 04 de setembro de 2010).

REZENDE, G. C. Ocupação agrícola e estrutura agrária no cerrado: o papel do preço da terra, dos recursos naturais e da tecnologia. Rio de Janeiro, IPEA, out./2002, 23p. (Texto para discussão n. 913), 2002.

RIBEIRO, E. M e GALIZONI, F. M. "Expansão da agropecuária e terras comuns: quatro casos nos cerrados de Minas Gerais". In: Anais do XLIII Congresso Brasileiro de Economia e Sociologia Rural (SOBER), Ribeirão Preto, p. 19. 2005.

SALIM, C. A. "As politicas econômica e tecnológica para o desenvolvimento agrário das áreas de cerrados no Brasil: avaliação e perspectivas". Brasília, Caderno de Difusão Tecnológica, v. 3, n. 2, maio/ago, p. 297-342, 1986.
SANTOS, M. A. A influência da dinâmica demográfica e domiciliar no processo de ocupação do Cerrado Brasileiro: o caso do Programa de Assentamento Dirigido do Alto Paranaíba, Minas Gerais, Brasil. Tese de Doutorado. Belo Horizonte, Cedeplar, Universidade Federal de Minas Gerais, p. 152. 1984.

SANTOS, M. A., BARBIERI, A. F. e CARVALHO, J. A. M. Ciclo de vida dos domicílios, mudanças no uso da terra e os movimentos migratórios nas regiões de fronteira agrícola no Cerrado brasileiro. In: Anais do XVI Encontro Nacional de Estudos Populacionais. Caxambu: ABEP, 2008.

SASAKI, L. I. Portal do Cerrado. Belo Horizonte, O Lutador, p. 344. 2008.

SAWYER, D. "Frontier expansion and retraction in Brazil". In: SCHMINK, M.; WOOD, C. (Org.). Frontier expansion in Amazônia. Gainesville: University of Florida Press. p. 180-203. 1984.

SAWYER, D. "População, meio ambiente e desenvolvimento sustentável no cerrado". In: HOGAN, D. J., et al. (org.). Migração e ambiente no Centro-Oeste. Campinas, NEPO/UNICAMP: PRONEX, p. 279-299. 2002.

SWINTON, S. M., ESCOBAR, G. e REARDON, T. "Poverty and Environment in Latin America: Concepts, Evidence and Policy Implication". World Development, v. 31, n.11, p. 1865-1872, nov 2003.

SILVA, L. L. "O papel do estado no processo de ocupação das áreas de cerrado entre as décadas de 60 e 80". Caminhos de Geografia, Uberlândia, v.1, n.2, p. 24-36, dez 2000.

THUNEN, J. H von. Isolated state. New York: Pergamon Press, [1966?]. 304 p.

VANWEY, L. K., GUEDES, G. R. e D'ANTONA, A. O. Land use change in Altamira settlement area, Pará, Brazil: patterns associated with property owner migration or ownership change. In: The Annual Meeting of the Population Association of America, Nova Orleans, Anais. Silver Spring, MD: PAA, 24 p, 2008.

WALKER, R. T., et al. "Land use and land cover change in forest frontiers: the role of household life cycles". International Regional Science Review, Philadelphia, v. 25, n. 2, p. 169-199, Apr., 2002.

WOUTERSE, F. e TAYLOR, J. E. "Migration and income diversification: evidence from Burkina Faso" World Development, Oxford, v. 36 n. 4, p. 625-640, Apr. 2008. 